\title{
$\mathbf{F} \cdot \mathbf{O} \cdot \mathbf{R} \cdot \mathbf{U} \cdot \mathbf{M}$ \\ Perspectives on Canadian Population
}

\section{Stationary population: Author's reply to comments by reviewers}

\author{
Anatole Romaniuk
}

I highly value the comments and reflections by professors Gilles Paquet and Roderic Beaujot on my Stationary population article. It is clear that the world is moving towards what I would call demographic maturity, whereby we live longer and healthier lives but bear ever-fewer children. This trend is good in itself, provided it does not turn into a permanent generational sub-replacement regime and, hence, depopulation in the absence of immigration. Indeed, Western countries are already turning to ever-growing immigration for their demographic sustainability. Sub-Saharan Africa, on the other hand, is still an exception to the demographic world trends. It is either in a pre-transitional regime or in a very early demographic transition, its population still growing by 2-3 per cent annually, and it is becoming the major supplier of migrants to Western Europe and North America.

As I stated in my article on the persistence of high fertility in tropical Africa, "For ordinary citizens (Africans), a nuclear family is not an alternative to extended kinship, with its deep-rooted sense of solidarity and lineage continuity. Moved by culture and tradition, and no less by economic rationality, they find support for their belief in the benefits of a large progeny for their own and their kin's well-being. At most, a minority seek to moderate procreation in the face of the challenges of modernity" (Romaniuk 2011: 21).

As for the comments, I regard them as full-fledged articles on the forecasting rather than addressing specific issues of my article, that is, on stationary population in Canada. Is advocated stationarity feasible, and if yes, is it desirable? Professor Paquet seems to see in forecasting or setting social targets for the future something of a Fata Morgana. As for myself, I see in the forecasting, generally done by the governments and international agencies, something akin to an analytical study exploring the future. Nonetheless, I find Professor Paquet's contribution interesting, for it broadens the debates regarding epistemological issues in the forecasting. As for Professor Beaujot's comments, they too are in many respects alternatives to my article on stationary population, and as such merit publication, as well. His comments are interesting and generally pertinent.

In my opinion, however, there is an undue infatuation with immigration in our Western society, and this is reflected in Professor Beaujot comments, as well. Immigration is being elevated as a solution to all problems - aging, work force deficit, international co-operation, technological progress. But in fact, all this can be achieved with minimal migration; no need for massive immigration. The case in point is Japan and other countries in Asia such as South Korea and Taiwan, known as "Asian economic tigers." Likewise, there is an undue infatuation with another ideologically driven construct in Western societies_-ethnocultural diversity. Diversity is hailed as the world's future, yet it is overlooked that diversity is often the source of the internal conflicts. Nor is diversity so warmly embraced in parts of the world other than the West. 


\section{References}

Romaniuk, A. 2011. Persistence of high fertility in Tropical Africa: The case of the Democratic Republic of the Congo. Population and Development Review 37(1):21. 